\title{
Obesity, viz a vis the gene, behavioural and environmental factors
}

\section{Opinion}

Obesity is one of the major health problems in world, ${ }^{1}$ and it is a disease of the young and the old. Obesity continues to increase worldwide with the United States of America having the highest prevalence. ${ }^{2}$ Like any other multifactorial diseases, obesity is a complex disease resulting from the interaction between the gene and the environment. The genetics account for $40 \%-70 \%$ of obesity as a condition. ${ }^{3}$ One of the most studied genetic variants concerning obesity is the FTO gene variant- rs9939609. Studies in both European and Asian population as implicated FTO gene variant- rs9939609. ${ }^{4}$ There is scarce data on the environmental and genetic associates of obesity in Africa. ${ }^{5}$ A recent pilot report has shown that environmental/ lifestyle factors like physical activity (PA), time spent sitting (TSS), and energy intake might be a significant mediator in the association between FTO rs9939609 and BMI in a Nigerian population6. The report was because they mediate the influence of FTO variant on BMI, offering new insight into the interrelationship between FTO genetic variants, TPA, energy intake and TSS in Nigeria. ${ }^{6}$

Despite limited studies in Nigeria on the genetics of obesity, it is thus imperative to pay more attention to its relationship with environmental correlates rather than focusing only on environmental variables like diet and physical activities. People with family history of obesity or overweight have a higher risk of been obese or overweight, and this increases with the degree of relatedness i.e. $1^{\text {st }}$ degree (Siblings etc), $2^{\text {nd }}$ degree (cousins) etc. With genetic predisposition and environmental interactions increases one's risk of obesity. In a Twin study by Hasselbalch ${ }^{7}$ gene-environment interaction models showed that high physical activity correlated with down-regulation of obesogenic genes. Another twin study has reported a significantly high correlation between genetic factor and differences in people's BMI. ${ }^{8}$ Some obesity related genes has been show to interact with consumption of fried food in people thereby increasing the risk obesity in them. ${ }^{2}$ Individual ways of modifying the environment strongly influence their risk of being obese as well, the twin study of Hasselbalch,7 indicated that association between sugar-sweetened soft drinks and obesity is controlled not only by genetic and shared environmental influences but by individually modifiable environment.

Therefore, having family history of obesity or possessing some gene variants associate of obesity in conjunction with environmental factors contribute to the development of obesity phenotype. Thus both genetic and environmental factors are germane on the initiation, progression and hallmark of obesity. Obesity prevention however require holistic approach that consider all predisposing factors.

\section{Acknowledgements}

None.
Volume 6 Issue 4 - 2017

\author{
Nanfizat Abiket Alamukii, ${ }^{1,2}$ Bolaji Fatai \\ Oyeyemi ${ }^{2,3}$ \\ 'Department of Zoology, University of Ibadan, Nigeria \\ ¿University College Hospital, University of Ibadan, Nigeria \\ ${ }^{3}$ International Centre for Genetic Engineering and \\ Biotechnology, India \\ ${ }^{4}$ Department of Science Technology, Nigeria
}

Correspondence: Nanfizat Abiket Alamukii, Cell Biology and Genetics Unit, Department of Zoology, University of Ibadan, Ibadan, Nigeria, Email iyabiket@gmail.com

Received: April 27, 2017| Published: May 01, 2017

\section{Conflict of interest}

The author declares no conflict of interest.

\section{References}

1. Finucane MM, Stevens GA, Cowan MJ, et al. National, regional, and global trends in body-mass index since 1980:Systematic analysis of health examination surveys and epidemiological studies with 960 country-years and 9.1million participants. Lancet. 2011;377(9765):557567.

2. Qi Q, Chu Ay, Kang JH, et al. Fried food consumption, genetic risk and body mass index: gene-diet interaction analysis in three US cohort studies. BMJ. 2014;348:1610.

3. GS Barsh, IS Farooqi, S Orahilly. Genetics of bodyweight regulation. Nature. 2000;404(6778):644-651.

4. Hennig BJ, Fulford AJ, Sirugo G, et al. FTO gene variation and measures of body mass in an African population. BMC Medical Genetics. 2009;10:21.

5. Chang YC, Liu PH, Lee WJ, et al. Common variation in the fat mass and obesity-associated (FTO) gene confers risk of obesity and modulates BMI in the chinese population. Diabetes. 2008;57(8):2245-2252.

6. Oyeyemi BF, Ologunde CA, Olaoye BA, et al. Physical activity, dietary habit and time spent sitting interact and have their mediating role on the effect of FTO rs9939609 polymorphism on obesity traits in Nigeria. Journal of Obesity. 2017:1-27.

7. Hasselbalch AL. Genetics of dietary habits and obesity- a twin study. Dan Med Bull. 2010;57(9):B4182.

8. Maes HH, Neale MC, Eaves LJ. Genetic and environmental factors in relative body weight and human adiposity. Behav Genet. 1997;27(4):325351. 